\title{
Proposta de Análise Praxeológica de Noções de Química em Documentos Oficiais e Livros Didáticos
}

\section{Proposal for Praxeological Analysis of Chemistry Notions in Official Documents and Textbooks}

\author{
(iD) Kleyfton Soares da Silva ${ }^{1}$ \\ iD Laerte Silva da Fonseca² \\ iD Luciano Pontes da Silva ${ }^{3}$ \\ iD Edmo Fernandes Carvalho ${ }^{4}$
}

\author{
'Instituto Federal Goiano (IF Goiano), Campos Belos, GO, Brasil. Autor correspondente: kleyfton.soares@ifgoiano.edu.br \\ ${ }^{2}$ Instituto Federal de Sergipe (IFS), Aracaju, SE, Brasil \\ ${ }^{3}$ Universidade Federal de Alagoas (UFAL), Arapiraca, AL, Brasil \\ ${ }^{4}$ Universidade Federal do Oeste da Bahia (UFOB), Barreiras, BA, Brasil.
}

Resumo: Este artigo traz a aplicação da Teoria Antropológica do Didático (TAD) na análise praxeológica da noção de Geometria Molecular (GM). O objetivo principal foi analisar a possibilidade de existência de relações praxeológicas que reforcem a necessidade da articulação entre objetos ostensivos e não ostensivos durante o ensino de GM. Esses objetos são compreendidos pela TAD, que toma como pressuposto a necessidade de tarefas que requisitam técnicas, tecnologias e teorias para colocarem o aluno em atividade matemática. No âmbito institucional analisaram-se documentos oficiais, e dois livros didáticos aprovados pelo Programa Nacional do Livro e do Material Didático (PNLD) também foram analisados quanto à existência de praxeologias. Diante dessas condições conclui-se que, no caso dos documentos oficiais, a noção de GM não está alicerçada em praxeologias. No entanto, quanto aos livros didáticos, verificou-se ser possível haver praxeologias que permitam colocar o aluno em atividade. molecular.

Palavras-chave: Praxeologia; Livro didático; Teoria antropológica do didático; Geometria

Abstract: This article brings the application of the Anthropological Theory of the Didactic (ATD) in the praxeological analysis of the notion of Molecular Geometry (MG). The main objective is to analyze the possibility of praxeological relations that reinforces the need for articulation between ostensive and non-ostensive objects during the teaching of MG. These objects are understood by ATD, which assumes the need for tasks that require techniques, technologies and theories to put the student in mathematical activity. At the institutional level, official documents are analyzed, and two textbooks approved by Programa Nacional do Livro e do Material Didático (PNLD) are also analyzed for the existence of praxeologies. Given these conditions, it is concluded that, in the case of official documents, the notion of MG is not based on praxeologies. However, as for the textbooks analyzed, it was found that it is possible to have praxeologies that allow the student to be active.

Keywords: Praxeology; Textbooks; Anthropological theory of the didactic; Molecular geometry.

Recebido em: 01/05/2019

Aprovado em: 28/08/2019 


\section{Introdução}

A Geometria Molecular (GM) é um conteúdo que desempenha um papel essencial na compreensão dos fenômenos químicos. Foi desenvolvida para justificar, inicialmente, a disposição espacial de átomos em uma molécula. Por meio de observações macroscópicas, cientistas já haviam previsto que o carbono poderia ter uma configuração tetraédrica, considerando-se que, dessa forma, compostos com a mesma fórmula molecular podem ter diferentes arranjos tridimensionais que Ihes conferem propriedades distintas (PAULING, 1960).

Com o desenvolvimento das técnicas de análise de estruturas moleculares hoje, sabese que padrões encontrados em arranjos moleculares podem ser estudados e preditos por meio de teorias que também se desenvolveram para explicar esse universo submicroscópico. A teoria mais conhecida por alunos do Ensino Médio é a Teoria da Repulsão dos Pares de Elétrons da Camada de Valência (TRPECV) que, conforme o próprio nome sugere, parte da compreensão de repulsão de pares de elétrons ligantes e não ligantes em torno de um átomo central para determinar a orientação espacial e, consequentemente, a geometria convencionada para a molécula em estudo.

No entanto, dificuldades de aprendizagem associadas à abstração do conteúdo em tela são reportadas com frequência (BOUSON, 2015). Primeiro, a TRPECV tem suporte em justificativas já consideradas controversas pelos estudantes, como é o caso da regra do octeto de Lewis, que apresenta exceções (contração e expansão à regra). Além disso, as noções não consolidadas acerca dos pares de elétrons ligantes e não ligantes, e de hibridização para justificar algumas ligações químicas, amplificam as dificuldades.

Embora os professores tenham se esforçado para tornar acessível alguns modelos manipuláveis (COSTA et al., 2015; LEANDRO et al., 2015; SANTANA; SILVA; BARROS, 2015), percebe-se que os alunos podem construir (mecanicamente) modelos corretos, mas que não estão associados a uma compreensão que leve em conta conceitos científicos. Terceiro, o trabalho com modelos tridimensionais requisita habilidades visuoespaciais que podem não estar disponíveis em nível satisfatório nas estruturas cognitivas dos alunos (SILVA, 2018).

Diante dessas questões, torna-se imprescindível analisar, no âmbito institucional, as pretensões de ensino relativas ao conteúdo GM, considerando-se que a imersão do aluno em uma atividade de química depende das estratégias adotadas pelo professor que, por sua vez, faz uso de documentos oficiais (parâmetros curriculares, livros didáticos, planos de ensino) para subsidiar suas práticas pedagógicas.

Dessa forma, é pertinente questionar os formatos de tarefas, sobretudo as apresentadas em livros didáticos, com o objetivo de direcionar as discussões conceituais para os lugares onde elas devem transitar: as exigências impostas aos alunos têm suporte em técnicas, tecnologias e teorias cobertas pelo ensino? quais justificativas teóricas não estão ao alcance do entendimento dos alunos e podem ser momentaneamente substituídas por artifícios didáticos (BITTAR, 2017)? os objetos ostensivos são capazes de evocar os objetos não ostensivos necessários para que o aluno entre em atividade?

Contudo, partindo da ideia de estudar as relações praxeológicas em livros didáticos (MENDES, 2015; REIS; SILVA, 2017; SILVA; HENRIQUES; SERÔDIO, 2017), o objetivo principal foi analisar a possibilidade de existência de relações praxelógicas que reforcem a necessidade da articulação entre objetos ostensivos e não ostensivos durante o ensino de GM. 


\section{Relações Praxelógicas entre Objetos Ostensivos e Não Ostensivos}

Como desdobramento das teorizações sobre a antropologia da Didática da Matemática, Chevallard $(1992,1994)$ apresenta alguns postulados (P) de um modelo de atividade humana:

$\mathrm{P}_{1}$ - toda atividade humana pode ser dividida em várias tarefas $(\mathrm{t}) ; \mathrm{P}_{2}$ - uma tarefa de um determinado tipo (T), podendo ser matemática, química, física ou extradisciplinar, como abrir uma porta, etc., desde que seja uma rotina sua realização necessita da implementação de uma técnica especifica $(\tau)$;

$\mathrm{P}_{3}$ - uma técnica deve parecer compreensível e justificável para ser viável, além de ser apoiada por um discurso que a justifique, chamado de discurso tecnológico ou tecnologia da técnica $(\theta)$;

$\mathrm{P}_{4}$ - a tecnologia de uma técnica deve parecer também compreensível e justificável, o que será chamada de teoria da tecnologia $(\Theta)$.

Esses quatro postulados referem-se ao que Chevallard (1994) denominou praxeologia ou organização praxeológica $[T, \tau, \theta, \Theta]$, que é a noção que indica a forma que se modela uma determinada atividade humana.

Costuma-se, de modo geral, tanto nas tarefas disciplinares em instituições de ensino, quanto naquelas que garantem nossa sobrevivência, ocorrer um processo de naturalização, tornando-as rotineiras e cristalizando o repertório de técnicas para resolvê-las. É assim, por exemplo, a tarefa de respirar. A naturalização dessa tarefa vital para o ser humano o faz pensar que respirar não seja uma tarefa, mas um gênero de tarefa. No ensino da matemática, bem como das ciências da natureza ou humanas em uma escola, costuma ocorrer o mesmo.

A repetição de um determinado tipo de tarefa, como resolver uma equação quadrática, costuma naturalizar esse processo de resolução e isso implica a ausência de compreensão do que está sendo realizado.

A produção de técnicas como uma ação cooperativa de estudantes e professores não ocorre em um ambiente de naturalização de tarefas. São as tarefas problemáticas que podem fazer emergir novas técnicas. Para Chevallard (1994), a tarefa precisa ser problemática para que surjam novas técnicas e esse é um trabalho essencial para o desenvolvimento da atividade institucional de um estudante. Esse é um postulado antropológico que diz respeito à ecologia de tarefas e técnicas (BOSCH; CHEVALLARD, 1999), ou seja, as condições e restrições que permitem a produção e o uso de técnicas em uma instituição.

Para existir em uma instituição, uma determinada técnica deve parecer compreensível, legível e justificada, uma restrição mínima que permite o controle e assegura a efetividade das tarefas (cooperativas) assumindo a colaboração dos diversos atores institucionais. Além disso, essa restrição implica a existência de um discurso que justifique as tarefas e técnicas (tecnologia da técnica).

Essa discussão sobre as tarefas e técnicas e discursos que as justifiquem evoca outra a respeito dos elementos que devem ter uma técnica, especialmente na passagem das tarefas de rotina para aquelas problemáticas. $E$, nesse sentido, na tentativa de observação da atividade humana, cabe uma explanação sobre os objetos ostensivos e não ostensivos e seus papéis nessa atividade. 
Os objetos ostensivos são caracterizados por Chevallard $(1992,1994)$ como aqueles que têm uma forma material, ou que é sensível a algo permanecendo não especificado. Um objeto material, tal como um lápis ou um caderno, por exemplo, é ostensivo. Mas são também gestos, palavras (discurso ostensivo), diagramas, desenhos, gráficos, a escrita (ostensivos escriturais).

A atividade humana, especialmente em uma instituição, cujo objetivo é a difusão de conhecimentos socialmente construídos, depende muito dos ostensivos, principalmente quando se trata da abordagem de objetos do saber que em sua maioria não têm materialidade em si. E, a respeito dessas noções (objetos a ensinar), surge a ideia do que sejam os objetos não ostensivos.

Um objeto não ostensivo, em contraste a um ostensivo, é o que Chevallard $(1992,1994)$ diz chamarmos de noções, ideias, conceitos. A rigor, não pode ser manipulado pelo sujeito sem o auxílio de um ostensivo, mas evocado.

Para ilustrar essa ideia, toma-se a noção de Geometria Molecular (GM). Uma pessoa que estude esse objeto do saber pode acreditar que existe, mas não poderá manipulá-lo, pois ele está no campo das ideias. Didaticamente, utilizar-se-ão ostensivos figurais, diagramas que expressem tal ideia, mas que não seja ela em si.

Diante de uma tarefa que evoque a noção de GM, qualquer que seja a técnica, envolverá a ativação de um complexo de objetos, ostensivos e não ostensivos, em um processo dialético, em que um depende do auxílio do outro, para que o sujeito apresente uma técnica eficientemente satisfatória para tal tarefa. Além disso, muito provavelmente na produção de uma técnica sejam necessários os ostensivos gestuais, escrituras, figurais e os discursos.

Supondo uma tarefa do tipo relacionar cada molécula com o tipo de geometria molecular adequada (quadro 1), uma técnica padrão implica conhecer algumas propriedades referentes à disposição dos átomos em uma molécula baseando-se na Teoria da Repulsão dos Pares de Elétrons da Camada de Valência (TRPECV), em que os elétrons presentes nas nuvens eletrônicas ao redor de um átomo central se afastam, provocando alteração no posicionamento dos átomos.

Quadro 1 - Tarefa relacionada à geometria molecular: associe molécula à geometria

\begin{tabular}{|l|l|}
\hline \multicolumn{2}{|l|}{ Associar molécula à geometria molecular } \\
\hline (1) $\mathrm{H}_{2} \mathrm{O}$ & ( ) trigonal plana \\
\hline (2) $\mathrm{CH}_{4}$ & ( ) angular \\
\hline (3) $\mathrm{NCl}_{3}$ & ( ) tetraédrica \\
\hline (4) $\mathrm{BF}_{3}$ & ( ) piramidal \\
\hline
\end{tabular}

Fonte: elaborado pelos autores.

Para relacionar o tipo de átomo ao ostensivo adequado que o representa, o estudante precisa mobilizar alguns não ostensivos que se inscrevem no campo das ideias e noções. Por exemplo, é necessário saber a estrutura do $\mathrm{NCl}_{3}$.

Essa molécula é composta por átomos de nitrogênio e cloro, os quais apresentam, respectivamente, cinco e sete elétrons (por serem dos grupos 15 e 17, respectivamente) em suas camadas de valência. Por esse motivo, o nitrogênio é o átomo central, pois necessita realizar o maior número de ligações (três) para atingir o octeto (regra do octeto, elemento da tecnologia, discurso que justifica a técnica para a tarefa descrita anteriormente). 
Cada átomo de cloro faz uma ligação química com o nitrogênio para atingir o octeto, pois já tem sete elétrons. Como o nitrogênio utiliza apenas três dos seus cinco elétrons de valência, sobra um par de elétrons não ligantes e o nitrogênio tem, então, três pares ligantes e um par não ligante, fatores que implicam afirmar que a molécula tetratômica do $\mathrm{NCl}_{3}$ apresenta geometria piramidal. Possivelmente, se esta tarefa apresentasse acompanhando o enunciado outro tipo de objeto ostensivo, como o figural, a associação ao tipo de geometria seria facilitada, conforme a Figura 1.

Figura 1 - Fórmula estrutural do $\mathrm{NCl}_{3}$

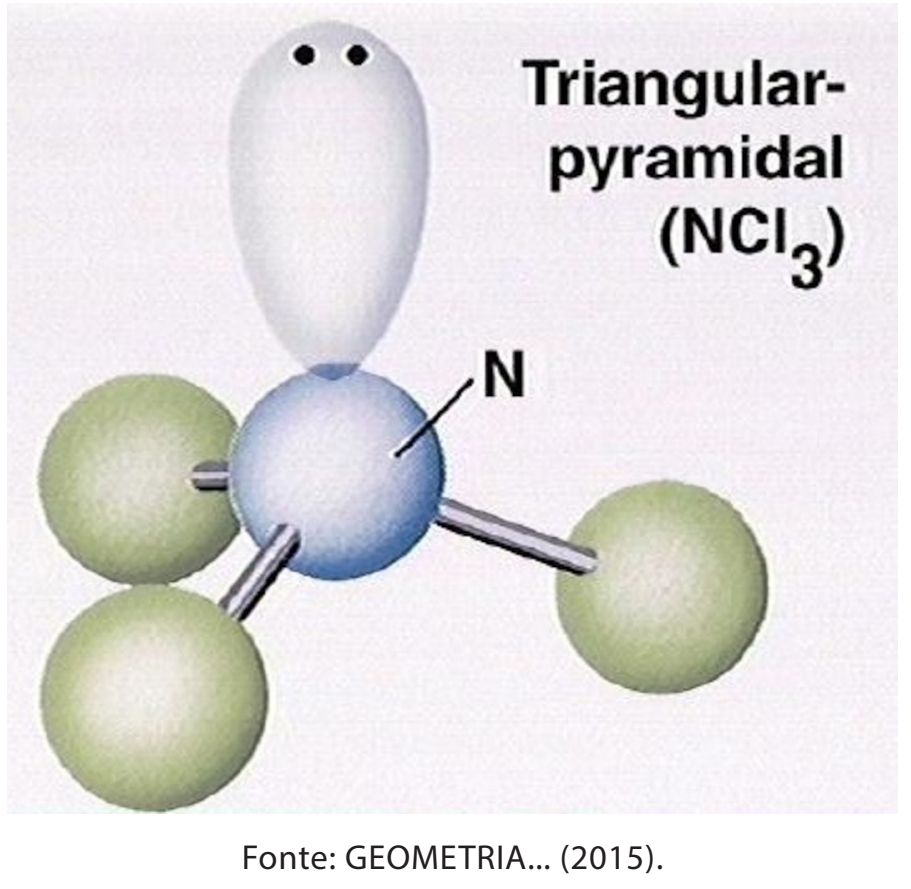

Retomando a ideia de analisar a GM, objeto da química que representa o formato adotado por uma molécula constituída por ligação covalente no plano espacial, são apresentadas no Quadro 2 as possíveis relações praxeológicas entre os objetos ostensivos e não ostensivos.

Quadro 2 - Grade de Análise de Referência

\begin{tabular}{|l|l|l|l|l|l|}
\hline \multicolumn{2}{|c|}{ Grade de análise para exame das possíveis relaçães praxelógicas entre objetos ostensivos e não ostensivos no ensino } \\
de geometria molecular
\end{tabular}

Fonte: elaborado pelos autores. 
Esse instrumento de análise vislumbra focalizar o papel dos ostensivos e não ostensivos na articulação entre os blocos do saber-fazer e do saber nas praxeologias institucionais e, por consequência, em uma atividade humana em determinada instituição. Na medida em que os ostensivos implicam a mediação dos não ostensivos e esse é um processo mútuo, pode-se dizer que não somente os ostensivos implicam as técnicas produzidas, mas também os não ostensivos, e o mesmo pode ser dito a respeito do discurso tecnológico, que sofre influência dos ostensivos utilizados na apresentação de uma técnica.

Nessa abordagem antropológica, que modela os saberes em termos de objetos e suas inter-relações, cabe um questionamento sobre a natureza dos objetos. O que constitui o conceito, por exemplo, de geometria molecular? Como podem ser descritas suas componentes? Se há uma busca pelo objeto primitivo da geometria molecular, pode-se facilmente inferir que o que se apresenta didaticamente como geometria molecular, estrutura de uma molécula composta de átomos, não é o objeto em si, mas uma representação desse objeto, fruto de atividades humanas em que outros objetos são colocados em jogo (BOSCH; CHEVALLARD, 1999).

As declarações sobre o objeto, sob a rubrica de 'definição' e o próprio nome deste são formas que, no Quadro 3, exemplificam as relações entre os objetos ostensivos e não ostensivos, bem como os blocos que compõem uma organização praxeológica. A própria forma de nomear um objeto já faz uso do ostensivo, assim, quando nos referimos ao não ostensivo, a ideia, o conceito de um determinado objeto do saber, já se utiliza um ostensivo para tal tarefa. No Quadro 3, utilizando outra tarefa, o instrumento de análise, ou seja, o funcionamento da grade de análise é mais bem discutido.

Quadro 3 - Exemplo do funcionamento da grade de análise

\begin{tabular}{|l|l|l|l|l|l|}
\hline \multicolumn{1}{|c|}{ Grade de análise para exame das possíveis relações praxelógicas entre objetos ostensivos e não ostensivos no ensino } \\
de geometria molecular
\end{tabular}

Fonte: elaborado pelos autores.

Os objetos ostensivos e não ostensivos descritos no Quadro 2 são necessários ao processo de descrição da implementação de uma das técnicas apresentadas, uma forma específica para resolver a tarefa: escrever a estrutura de Lewis para a molécula $\mathrm{XeF}_{4^{\prime}}$ prevendo a geometria molecular. 
Esses ostensivos não podem ser pensados apenas como materiais, mas, segundo Bosch e Chevallard (1999), como sensíveis, adquirindo para o ser humano uma realidade perceptível. É preciso manipular adequadamente tais ostensivos para que se tenha acesso aos não ostensivos, ou seja, a estrutura de Lewis para representação da geometria molecular pode ser acessada pelos ostensivo figural e escritural. Essa ostensividade se refere em geral a todos os sentidos e a articulação entre esses diferentes objetos contribui de maneira expressiva ao acesso a noções, ideias, intuições, teoremas, etc.

É preciso lembrar que nessa teorização proposta no âmbito da antropologia da Didática da Matemática, um objeto existe somente se existem instituições e pessoas que se relacionam com esse objeto (BOSCH; CHEVALLARD, 1999), implicando a descrição das práticas das organizações praxeológicas. Os conceitos referentes à geometria molecular emergem dessas praxeologias.

\section{Análise de Documentos Oficiais Referentes à Proposta de Ensino de Geometria Molecular}

Uma análise prévia das competências e habilidades constantes nos Parâmetros Curriculares Nacionais (PCN) referentes ao programa de ensino de química revela que a noção de geometria molecular pode ser considerada no nível de gênero de tarefas: "[...] compreender os códigos e símbolos próprios da Química atual. Compreender e utilizar conceitos químicos dentro de uma visão macroscópica (lógico empírica)". (BRASIL, 2000, p. 39).

A compreensão de fórmulas moleculares, por exemplo, bem como suas representações no plano tridimensional, requer que a noção de espacialidade das moléculas seja contemplada nos currículos. Da mesma forma, para entendermos fenômenos macroscópicos, tais como polaridade e solubilidade, precisamos compreender a estrutura da matéria e suas configurações espaciais. Assim, esse primeiro documento oficial, ainda que de forma implícita, orienta a construção de tipos de tarefas relativas à GM, mas não revela técnicas, tecnologias e teorias, não sendo possível identificar, portanto, uma praxeologia.

No próximo documento, PCN+Ensino Médio (BRASIL, 2002), criado para complementar as informações dos PCN (BRASIL, 2000), verifica-se que as competências e habilidades visadas pelo ensino de química foram mais bem discriminadas. Encontrou-se, dentro do quadro de competências e habilidades referentes aos modelos explicativos e representativos, o seguinte gênero de tarefas: "Elaborar e utilizar modelos científicos que modifiquem as explicações do senso comum; por exemplo, a ideia de que óleo e água não se misturam devido a diferenças de densidade e não por questões de interação entre partículas." (BRASIL, 2002, p. 91).

Ainda sobre o mesmo documento, na seção que trata dos temas estruturadores do ensino de química - temas 2 e 8 , unidades temáticas 2 e 2, respectivamente - verificam-se os seguintes gêneros de tarefas: (a) "Representar as substâncias e as transformações químicas a partir dos códigos, símbolos e expressões próprios da Química". (BRASIL, 2002, p. 97); e (b) "Aplicar ideias sobre arranjos atômicos e moleculares para entender a formação de cadeias, ligações, funções orgânicas e isomeria". (BRASIL, 2002, p. 105).

Mais uma vez, os gêneros de tarefas identificados nos documentos oficiais citados apenas mostram possíveis aberturas para a introdução do conteúdo GM. Como é o caso do exemplo que cita o fenômeno da imiscibilidade de óleo em água devido às interações intermoleculares dos compostos em questão. 
A polaridade desses compostos está intrinsecamente associada à configuração espacial das moléculas, sendo, portanto, a contemplação do conteúdo de GM indispensável para satisfazer a exigência do documento.

Outro documento analisado, Orientações Curriculares para o Ensino Médio (BRASIL, 2006, p. 114), enfatiza os mesmos gêneros de tarefas apontados nos PCN+ (BRASIL, 2002). Sobre a Base Nacional Comum Curricular (2018), vejamos o que o documento revela para a competência específica 1:

[...] Dessa maneira, podem-se estimular estudos referentes a: estrutura da matéria; transformações químicas; leis ponderais; cálculo estequiométrico; princípios da conservação da energia e da quantidade de movimento; ciclo da água; leis da termodinâmica; cinética e equilíbrio químicos; fusão e fissão nucleares; espectro eletromagnético; efeitos biológicos das radiações ionizantes [...]. (BRASIL, 2018, p. 554 , grifo nosso).

Relativamente ao conteúdo de GM, encontrou-se no termo "estrutura da matéria" a possibilidade de estudo desse conteúdo. Verifica-se, portanto, que em todos os documentos oficiais consultados não foi possível identificar tipos de tarefas que permitam ao aluno entrar em ação por meio de uma atividade de química conforme os postulados de Chevallard (1994). Dessa forma, a incompletude dos elementos constituintes de uma organização praxeológica $[\mathrm{T}, \tau, \theta, \Theta]$ nos permite afirmar que não há, sob as lentes de Chevallard (1994), praxeologias nos documentos oficiais para o ensino de química, podendo causar, a depender do ponto de vista, desorientação na organização do currículo escolar.

\section{Análise de Livros Didáticos Aprovados pelo PNLD}

Na avaliação do Programa Nacional do Livro Didático (PNLD) de 2018 optou-se pela análise de apenas dois livros de química, levando-se em consideração que os livros aprovados pelo PNLD compartilham de características similares. Dentre eles: Química cidadã (SANTOS, 2016) e Ser protagonista (LISBOA et al., 2016).

Seguindo as orientações de Chevallard (1994), para desenvolver uma análise praxeológica, escolheu-se, para exemplificar, um tipo de Tarefa que diz respeito à noção de GM. Justifica-se o tipo de Tarefa escolhido para análise pela natureza mínima e necessária à compreensão de GM.

Nesse sentido, para ambos os exemplos que seguem, o tipo de Tarefa se apresenta como: Determinar a geometria molecular a partir do átomo central indicado na fórmula química (T).

Exercício sobre GM

65. As espécies $\mathrm{SO}_{2}, \mathrm{SO}_{3^{\prime}} \mathrm{BF}_{3^{\prime}} \mathrm{NF}_{3}$ e $\mathrm{CF}_{4^{\prime}}$ todas no estado gasoso, contêm, respectivamente, a seguinte geometria molecular:

\footnotetext{
(a) Angular, linear, triangular, piramidal e tetraédrica;

(b) Angular, piramidal, triangular, piramidal e tetraédrica;

(c) Angular, triangular, triangular, piramidal e tetraédrica;

(d) Linear, piramidal, triangular, triangular e quadrado planar;

(e) Angular, triangular, triangular, triangular e quadrado planar.
}

Fonte: Santos (2016, p. 249).

Exercício sobre GM

14. Relacione as moléculas com as respectivas geometrias moleculares. Dados números atômicos $\mathrm{H}(\mathrm{Z}=1), \mathrm{C}(\mathrm{Z}=7)$, $\mathrm{O}(\mathrm{Z}=8), \mathrm{F}(\mathrm{Z}=9), \mathrm{S}(\mathrm{Z}=16)$

Coluna I:

(geometria molecular)

(a) linear

(b) angular

(c) trigonal plana

(d) pirâmide trigonal

(e) tetraédrica

$\begin{aligned} & \text { Coluna II } \\ & \text { (moléculas) }\end{aligned}$
I. $\mathrm{SO}_{3}$
II. $\mathrm{NH}_{3}$
III. $\mathrm{CO}_{2}$
IV. $\mathrm{SO}_{2}$
V. $\mathrm{CF}_{4}$


Desse ponto em diante, prosseguiremos à análise praxeológica, identificando as técnicas, tecnologias e teorias relativas ao tipo de Tarefa citado (Quadro 4).

Quadro 4 - Aplicação da grade de análise nos dois livros didáticos selecionados, tomando como base as Figuras 3 e 4 (F3 e F4), respectivamente

\begin{tabular}{|c|c|c|c|c|c|}
\hline \multicolumn{6}{|c|}{$\begin{array}{c}\text { Grade de análise para exame das possíveis relações praxelógicas entre objetos ostensivos e não ostensivos no ensino } \\
\text { de geometria molecular }\end{array}$} \\
\hline \multicolumn{2}{|c|}{ Bloco do Saber-Fazer (BSF) } & \multicolumn{2}{|c|}{ Articulação entre BSF-BS } & \multicolumn{2}{|c|}{ Bloco do Saber (BS) } \\
\hline Tipo de Tarefa (T) & Técnica $(\tau) \hookleftarrow$ & Objeto ostensivg & $\begin{array}{l}\text { Objeto não } \\
\text { ostensivo }\end{array}$ & $\Rightarrow$ Tecnologia $(\theta)$ & Teoria $(\Theta)$ \\
\hline $\begin{array}{l}\text { Determinar a geome- } \\
\text { tria molecular a par- } \\
\text { tir do átomo central } \\
\text { indicado na fórmula } \\
\text { química. }\end{array}$ & $\begin{array}{l}\tau_{1 F 3} \text { : Não identificada. } \\
\tau_{1 F 4} \text { : Escreva a fórmula } \\
\text { eletrônica da molécula } \\
\text { e identifique o átomo } \\
\text { central; Faça a distribui- } \\
\text { ção espacial dos pares } \\
\text { de elétrons da camada } \\
\text { de valência ao redor } \\
\text { do átomo central. Ga- } \\
\text { ranta que os pares de } \\
\text { elétrons estejam com a } \\
\text { máxima distância pos- } \\
\text { sível entre eles (teoria } \\
\text { da repulsão dos pares } \\
\text { eletrônicos); Para defi- } \\
\text { nir a geometria observe } \\
\text { a distribuição espacial } \\
\text { dos átomos envolvidos } \\
\text { (LISBOA et al., 2016, p. } \\
\text { 138). }\end{array}$ & $\begin{array}{l}\text { (a) materiais: lápis, } \\
\text { papel; } \\
\text { (b) escritural: pala- } \\
\text { vras, fórmulas quí- } \\
\text { micas variadas. }\end{array}$ & $\begin{array}{l}\text { (a) noções da re- } \\
\text { gra do octeto; } \\
\text { (b) noções de re- } \\
\text { pulsão eletrônica. }\end{array}$ & 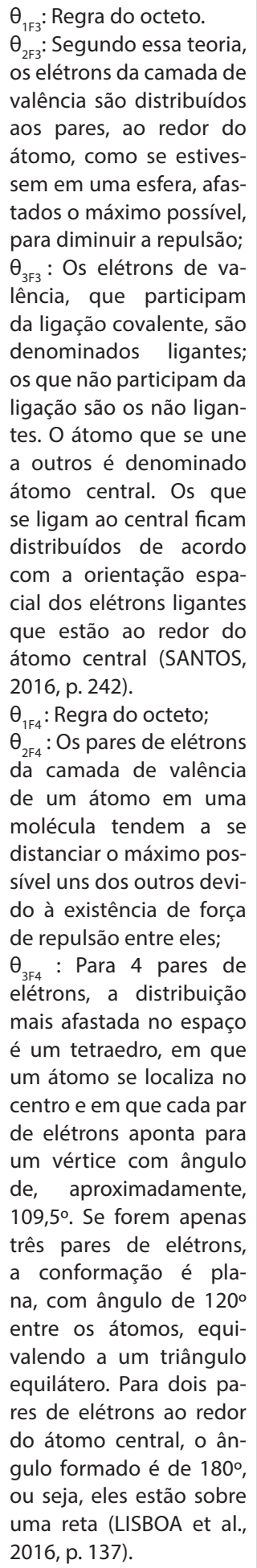 & $\begin{array}{l}\text { Teoria da Repul- } \\
\text { são dos Pares de } \\
\text { Elétrons da Ca- } \\
\text { mada de Valência } \\
\text { (TRPECV). }\end{array}$ \\
\hline
\end{tabular}

Fonte: elaborado pelos autores. 
A partir do exemplo do livro de Santos (2016), perceberam-se algumas lacunas que inviabilizam a existência de uma praxeologia $\left(T, \tau_{1 F 3}\right)$, pontualmente, ausência de técnicas que auxiliam a resolução da tarefa dada. Em nosso entendimento, a inexistência de técnicas implica dificuldades do uso do livro didático pelo aluno, uma vez que a máxima dependência pelo professor pode representar um obstáculo de aprendizagem autônoma.

Outro ponto a ser destacado se refere a tecnologias $(\theta)$ insuficientes para a compreensão das noções apresentadas. Por exemplo, para a determinação da geometria molecular, pelos menos três tecnologias precisam estar disponíveis ao longo da obra $\left(\theta_{13^{\prime} 3^{\prime}}, \theta_{2 \mathrm{~F}^{\prime}} \theta_{2 \mathrm{~F} 4^{4}}\right)$ : as noções de regra do octeto/ estrutura de Lewis; repulsão dos pares eletrônicos, e disposição espacial das moléculas e seus ângulos entre ligações. Na obra de Santos (2016), as definições acerca dos ângulos entre ligações estão incompletas, no sentido de não justificar, em momento oportuno, a formação de ângulos.

A forma estrutural plana do metano pode sugerir que as ligações químicas nessa
molécula fazem, entre si, um ângulo de $90^{\circ}$ (veja quadro abaixo), quando, na verdade,
a molécula de metano tem os átomos de hidrogênio posicionados nos vértices de
um tetraedro regular, com o átomo de carbono no centro. Os ângulos das ligações
formadas entre os átomos $\mathrm{HCH}$ são todos iguais a 109,50. (SANTOS, 2016, p. 240,
grifo nosso).

Observa-se que não se justifica a formação de ângulos de 109,5 nas ligações $\mathrm{HCH}$ do metano, podendo representar um obstáculo para o aluno iniciante, que só depois será apresentado à noção de repulsão do par eletrônico. Talvez, a escolha do autor em abordar primeiramente o conteúdo 'polaridade', antes de 'geometria molecular', traga algum prejuízo durante a aprendizagem dessa noção.

Em contrapartida, o capítulo analisado da obra de Lisboa et al. (2016), com base no exemplo mínimo, apresenta uma praxeologia $[T, \tau, \theta, \Theta]$. Ou seja, o bloco do saber-fazer dialoga com o bloco do saber, tendo em vista que o tipo de Tarefa $(T)$, pode ser resolvido por pelo menos uma técnica $\left(\tau_{1 F 4}\right)$, justificada por três tecnologias $\left(\theta_{1 \mathrm{~F}^{\prime}} \theta_{2 \mathrm{~F} 4^{\prime}}, \theta_{3 \mathrm{~F} 4}\right)$, que estão alicerçadas em uma teoria $(\Theta)$. Nesse caso, pode-se dizer que o aluno pode entrar em atividade para resolver tarefas de química.

\section{Considerações Finais}

A análise praxeológica das noções de geometria molecular se mostrou efetiva quando se utilizou a Teoria Antropológica do Didático enquanto ferramenta metodológica. As questões discutidas no âmago desta pesquisa revelaram que conteúdos de química podem ser analisados segundo uma lógica didático-pedagógica que considera a articulação dos blocos do saber-fazer e do saber em favor da aprendizagem.

Cabe destacar que, devido à inviabilidade de análise de outros elementos presentes no livro didático pela TAD, tais como a qualidade gráfica e o tratamento textual, é importante vislumbrar métodos complementares. Assim, é possível identificar praxeologias em livros didáticos que diferem em estratégias didáticas, podendo representar ganhos de conhecimentos em níveis distintos em decorrência do formato de apresentação do material. 
Por exemplo, o livro de Santos (2016) não traz representações tridimensionais no item que trata das geometrias moleculares, elementos ilustrativos essenciais para a transição de múltiplas representações em química. A percepção visuoespacial depende, em grande parte, das experiências vivenciadas pelos estudantes, sendo as representações tridimensionais, portanto, atrativos indispensáveis para mobilizar o foco da atenção e construir memórias visuoespaciais.

Tais características aparecem contempladas na proposta de Lisboa et al. (2016), quando apelam pelo visual e experimental, ao sugerirem uma atividade prática para a construção de moléculas tridimensionais com materiais alternativos.

Em suma, em termos de uma organização química ou praxeológica, mostrou-se que um livro didático está mais compatível com os pressupostos de Chevallard (1994) para que tarefas sejam resolvidas com êxito, tendo em vista que foi possível identificar a existência de técnicas, tecnologias e teorias que dão suporte a elas.

\section{Referências}

BOSCH, M.; CHEVALLARD, Y. La sensibilité de l'activité mathématique aux ostensifs. Recherches en Didactique des Mathématiques, Grenoble, v. 19, n. 1, p. 77-124, 1999. Disponível em: http://yves. chevallard.free.fr/spip/spip/IMG/pdf/Sensibilite_aux_ostensifs.pdf. Acesso em: 26 abr. 2020.

BOUSON, J. D. Metodologias didáticas alternativas para o ensino de geometria molecular e soluções: estratégias para a construção do conhecimento. 2015. 74 f. Dissertação (Mestrado) - Universidade Federal Fluminense, Niterói, 2015.

BRASIL. Ministério da Educação. Base nacional comum curricular: ensino médio. Brasília: MEC, 2018.

BRASIL. Ministério da Educação. Orientações curriculares para o ensino médio: v. 2 ciências da natureza, matemática e suas tecnologias. Brasília: MEC, 2006.

BRASIL. Ministério da Educação. Parâmetros curriculares nacionais: ensino médio. Brasília: MEC, 2000.

BRASIL. Ministério da Educação. PCN+ ensino médio: orientações educacionais complementares aos parâmetros curriculares nacionais ciências da natureza, matemática e suas tecnologias. Brasília: MEC, 2002.

BITTAR, M. A teoria antropológica do didático como ferramenta metodológica para análise de livros didáticos. Zetetike, Campinas, v. 25, n. 3, p. 364-387, 2017. DOI: https://doi.org/10.20396/zet. v25i3.8648640

CHEVALLARD, Y. Concepts fondamentaux de la didactique: perspectives apportées par une approche anthropologique. Recherches en Didactique des Mathématiques, Grenoble, v. 12, n. 1, p. 73$112,1992$.

CHEVALLARD, Y. Ostensifs et non-ostensifs dans l'activité mathématique. In: SEMINAIRE DE L'ASSOCIAZIONE MATHESIS, 1994, Turin. Actes [...]. [Turin]: Mathesis: Società Italiana di Scienze Matematiche e Fisiche, 1994. p. 190-200. Disponível em: http://yves.chevallard.free.fr/spip/spip/ article.php3?id_article=125. Acesso em: 6 abr. 2019.

COSTA, K. L.; ARAÚJO, N. F.; JEFFREYS, M. F.; SANTOS, V. O. Uso de aplicativo no ensino de química para o estudo da geometria molecular. In: SIMPÓSIO BRASILEIRO DE QUÍMICA, 55., 2015, Goiânia. Anais [...].Disponível em: http://www.abq.org.br/cbq/2015/trabalhos/6/8066-21454.html. Acesso em: 6 abr. 2019. 
GEOMETRIA molecular. 2015. Disponível em: http://geometriamoleculartie.blogspot.com/. Acesso em: 22 mar. 2020.

LEANDRO, D. T. L. T et al. Aprendendo os modelos atômicos, através de práticas lúdicas: uma experiência realizada pelos alunos do PIBID, na EREM São Sebastião, Ouricuri-PE. In: SIMPÓSIO BRASILEIRO DE EDUCAÇÃO QUÍMICA, 13, 2015, Fortaleza. Anais [...]. Rio de Janeiro, ABQ, 2015. Disponível em: http://www.abq.org.br/simpequi/2015/trabalhos/91/7007-15925.html. Acesso em: 6 abr. 2019.

LISBOA, J. C. F. et al. (coord.). Ser protagonista: química: ensino médio, $1^{\circ}$ ano. 3. ed. São Paulo: Edições SM, 2016. v. 1.

MENDES, H. L. Análise praxeológica de livro didático de matemática referente ao estudo de números binários. REVEMAT, Florianópolis, v. 10, n. 1, p. 199-219, 2015. DOI: https://doi. org/10.5007/1981-1322.2015v10n1p199

PAULING, L. The nature of the chemical bond and the structure of molecules and crystals: an introduction to modern structural chemistry. 3rd. ed. New York: Cornell University Press, 1960.

REIS, E. S.; SILVA, V. Análise de livro didático do ensino fundamental: um olhar na geometria apresentada a partir da história da matemática. Revista Saberes da Unijipa, Ji-Paraná, v. 5, n. 1, p. 4968, 2017. Disponível em: https://unijipa.edu.br/por-que-a-unijipa/revista-saberes/edicao-5/. Acesso em: 6 abr. 2019.

SANTANA, E. M.; SILVA, E. L.; BARROS, V. P. Compreensão da polaridade das moléculas através de modelos moleculares didáticos. In: SIMPÓSIO BRASILEIRO DE EDUCAÇÃO QUÍMICA, 13., 2015, Fortaleza. Anais [...]. Rio de Janeiro: ABQ, 2015. Disponível em: http://www.abq.org.br/ simpequi/2015/trabalhos/90/6655-20305.html. Acesso em: 6 abr. 2020.

SANTOS, W. L. P. (coord.). Química cidadã: química: ensino médio, 1. a série. 3. ed. São Paulo: Editora AJS, 2016. v. 1.

SILVA, H. L.; HENRIQUES, A.; SERÔDIO, R. P. Análise praxeológica de funções trigonométricas em um livro didático do ensino médio. Perspectivas da Educação Matemática, Campo Grande, v. 10, n. 22, p. 409-432, 2017. Disponível em: https://periodicos.ufms.br/index.php/pedmat/article/view/2286. Acesso em: 6 abr. 2020.

SILVA, K. S. A neurociência cognitiva como base da aprendizagem de geometria molecular: um estudo sobre atributos do funcionamento cerebral relacionados à memória de longo prazo. 2018. $200 \mathrm{f}$. Dissertação (Mestrado Acadêmico em Ensino de Ciências e Matemática) - Universidade Federal de Sergipe, São Cristóvão, 2018. 